\title{
Análise da ocupação desordenada no alto da Macaíba em Jaboatão dos
}

\section{Guararapes/PE}

\author{
Analysis of disordered occupation in upper Macaíba in Jaboatão dos Guararapes/PE \\ Análisis de la ocupación desordenada en Macaíba alta de Jaboatão dos Guararapes/PE
}

Recebido: 04/12/2021 | Revisado: 10/12/2021 | Aceito: 11/12/2021 | Publicado: 20/12/2021

\author{
Maria Cristina Alves de Lima \\ ORCID: https://orcid.org/0000-0002-2166-0273 \\ Universidade de Pernambuco, Brasil \\ E-mail:mcal@poli.br \\ Sanderson Damascena de Jesus \\ ORCID: https://orcid.org/0000-0002-8249-992X \\ Universidade de Pernambuco, Brasil \\ E-mail: sdj@poli.br \\ Kalinny Patrícia Vaz Lafayette \\ ORCID: https://orcid.org/0000-0002-7954-2317 \\ Universidade de Pernambuco, Brasil \\ E-mail: klafayette@poli.br \\ Simone Rosa da Silva \\ ORCID: https://orcid.org/0000-0001-7138-7546 \\ Universidade de Pernambuco, Brasil \\ E-mail: simonerosa@poli.br
}

\begin{abstract}
Resumo
Os centros urbanos evoluem a partir de uma série de fatores que se relacionam promovendo crescimento. Fatores de ordem econômica e socioambiental devem ter associação harmônica e proporcional, a fim de um crescimento urbano ordenado, que promova espaços planejados e estruturados, capazes de prover a seus moradores uma infraestrutura adequada. No geral o crescimento se dá em meio ao descompasso desses fatores, gerando ocupações desordenadas. Questões como drenagem urbana, pavimentação e saneamento básico, funcionam muitas vezes de forma precária, quando não, a população vive desprovida dessas estruturas urbanísticas. O objetivo do presente artigo é apresentar uma análise de ocupação do solo, no morro da Macaíba, localizado no bairro de Cavaleiro, no município de Jaboatão dos Guararapes/PE. O estudo buscou verificar o processo de ocupação do local, por meio de uma análise comparativa dos dados quantitativos e qualitativos, ocorridos em dois momentos distintos: antes da implantação da linha Centro-2 do metrô Recife e depois de sua implantação. Verificou-se os impactos de avanço da mancha urbana, solo exposto e supressão de área verde, utilizando-se para geração dos dados quantitativos, imagens vetorizadas a partir de ortofotocartas dos períodos estudados. Foi evidenciado que a ocupação urbana teve um incremento de 55,22\%, enquanto as áreas expostas e a cobertura vegetal tiveram uma redução de 17,54\% e 37,39\%, respectivamente.
\end{abstract}

Palavras-chave: Ocupação desordenada; Risco; Impacto ambiental; Análise temporal.

\begin{abstract}
Urban centers evolve from a series of factors that are related to promoting growth. Economic and socio-environmental factors must have a harmonious and proportional association in order for an orderly urban growth, which promotes planned and structured spaces, capable of providing its residents with adequate infrastructure. In general, growth takes place amidst the mismatch of these factors, generating disorderly occupations. Issues such as urban drainage, paving and basic sanitation often work in a precarious way, when not, the population lives without these urban structures. The aim of this article is to show an analysis of land occupation in the Morro da Macaíba, located in the neighborhood of Cavaleiro, in the municipality of Jaboatão dos Guararapes/PE. The study sought to verify the process of occupation of the site, through a comparative analysis of quantitative and qualitative data, which occurred at two different times: before the implementation of the Centro-2 line of the Recife subway and after its implementation. It was verified the impacts of urban sprawl, exposed soil and green area suppression, using vectorized images from orthophotocharts of the studied periods to generate quantitative data. It was shown that urban occupation had an increase of $55.22 \%$, while exposed areas and vegetation cover had a reduction of $17.54 \%$ and $37.39 \%$, respectively.
\end{abstract}

Keywords: Disorderly occupation; Risk; Environmental impact; Temporal analysis.

\section{Resumen}

Los centros urbanos evolucionan a partir de una serie de factores que se relacionan favoreciendo el crecimiento. Los factores económicos y socioambientales deben tener una asociación armónica y proporcional para un crecimiento 
urbano ordenado, que promueva espacios planificados y estructurados, capaces de dotar a sus residentes de una infraestructura adecuada. En general, el crecimiento se da en medio del desajuste de estos factores, generando ocupaciones desordenadas. Temas como el drenaje urbano, la pavimentación y el saneamiento básico suelen funcionar de manera precaria, cuando no, la población vive sin estas estructuras urbanas. El objetivo de este artículo es mostrar un análisis de la ocupación del suelo en el Morro da Macaíba, ubicado en el barrio de Cavaleiro, en el municipio de Jaboatão Guararapes / PE. El estudio buscó verificar el proceso de ocupación del sitio, a través de un análisis comparativo de datos cuantitativos y cualitativos, que ocurrió en dos momentos diferentes: antes de la implementación de la línea Centro-2 del metro de Recife y después de su implementación. Se verificaron los impactos de la expansión urbana, suelos expuestos y supresión de áreas verdes, utilizando im á genes vectorizadas de ortofotografías de los períodos estudiados para generar datos cuantitativos. Se demostró que la ocupación urbana tuvo un incremento del 55,22\%, mientras que las áreas expuestas y la cobertura vegetal tuvieron una reducción del 17,54\% y $37,39 \%$, respectivamente.

Palabras clave: Ocupación desordenada; Riesgo; Impacto ambiental; Análisis temporal.

\section{Introdução}

A dinâmica da expansão urbana e o modo como ela impacta o meio ambiente, vem reduzindo a vegetação nativa e permitindo contínuo processo de ocupação do solo de forma irregular em encostas, causando diversos problemas e colocando em risco a vida dos moradores (Cerqueira et al., 2021).

O dinamismo das cidades provocado pelo crescimento demográfico não é acompanhado pelo desenvolvimento da infraestrutura urbana, fazendo com que a parcela mais pobre da população sofra as consequências provocadas pela ocupação dessas áreas propensas a riscos (Zambon \& Salvati, 2018; Silva et al., 2019).

No Brasil, a urbanização tem sido desafiadora. À medida em que a modernização do país avança, em contrapartida um forte modelo de exclusão cresce, favorecendo a desigualdade social, condições de vida de baixa qualidade e crescimento populacional sem planejamento urbano (Silveira et al., 2019).

Regiões de grandes relevos precisam de amparo técnico de engenharia e controle urbanístico, visando mitigar a ocorrência de desastres por movimentação de massas (Assis et al., 2017). Ações antrópicas como cortes de talude, supressão da vegetação existente, lançamento de efluentes diretos na encosta e deposição irregular de resíduos, não só interferem o meio como podem causar desastres, um exemplo é o deslizamento de terra (De Lima Andrade; Calheiros \& Conceição, 2019; Gori et al., 2019).

No Brasil e em outros países em desenvolvimento, a questão ambiental está associada à deficiência na gestão dos Resíduos Sólidos Urbanos - RSU (Araújo et al., 2018). A disposição inadequada dos resíduos sólidos pode gerar pequenos lixões nas áreas urbanas das cidades brasileiras, dispondo de uma variedade de resíduos como os compostos orgânicos voláteis, pesticidas, solventes, metais pesados, entre outros (Silva et al., 2020).

Atualmente os riscos, devido a deposição irregular de resíduos, tornou-se mais preocupante, pois elementos sintéticos e perigosos aos ecossistemas e à saúde humana, encontram-se incorporados à composição das novas tecnologias que estão sendo descartados a céu aberto (Gouveia et al., 2019). Além dos impactos visuais provocados por esses lixões, existe a proliferação de vetores (moscas, mosquitos, baratas, ratos etc.) e a contaminação do solo e da água (Reis et al., 2017).

Na prática os resíduos são vistos como uma parcela da cadeia econômica global e sua reciclagem ou reaproveitamento é conveniente, sustentável e essencial. Para que isso seja de fato efetivado é preciso um sistema de gestão de resíduos integrado a indústria e ao ambiente urbano. Atualmente, o gerenciamento de resíduos é autônomo e desconectado da indústria. A gestão dos resíduos sólidos deve ser projetada para aumentar a conexão com a economia tradicional (Cremiato et al., 2018).

Os cursos de água também são impactados pela ocupação irregular desordenada e pelos RSU. O lixo pode aumentar o risco de bloqueio do sistema de drenagem. Basso et al. (2018) menciona que as alterações do uso do solo, dependendo da intervenção, pode ser caracterizada como uma forma de agressão antrópica em corpos hídricos, pois a implementação de 
construções e edificações aumentam a impermeabilização da superfície, diminuindo a infiltração da água no solo, consequentemente, diminuindo também a recarga do lençol freático. Conforme Pessoa Neto et al. (2020), de forma geral, a concepção da modificação do ambiente é fundamental para a gestão e controle das questões ambientais, econômicas e sociais.

Diante do exposto, faz-se necessário compreender a relação que se estabelece entre o processo de urbanização desordenada e as formas de uso e ocupação do solo nas encostas, levando em consideração que a urbanização das cidades é crescente e dinâmica. Fatores como supressão da cobertura vegetal, disposição irregular de RSU, sistema de drenagem deficiente, falta de coleta e tratamento de águas residuais domésticas, costumam determinar os riscos de uma localidade. Realizar uma análise temporal da expansão urbana, sem critério de planejamento, e os impactos socioambientais provocados pela deposição de resíduos são alguns dos interesses desse estudo.

Sendo assim, objetiva-se com essa pesquisa realizar uma análise temporal de ocupação do solo, em uma área do município de Jaboatão dos Guararapes/PE, levando em consideração a implantação da linha Centro-2 do metrô Recife. Nesse estudo, busca-se verificar o avanço da mancha urbana, solo exposto e supressão vegetal da localidade, considerando o período antes e depois do início de operação da linha Centro-2. Para isso, utilizou-se de dados qualitativos e quantitativos, gerados pelas imagens vetorizadas das ortofotocartas. Também se determinou o grau de risco ambiental da encosta.

\section{Referencial Teórico}

\section{Ocupações Desordenadas}

As transformações urbanas vêm avançando e analisar as causas, os efeitos ambientais e sociais desse processo são urgentes (Ramón González \& Aguilar, 2021). No Brasil é muito comum encontrar ocupações irregulares, inclusive na Região Metropolitana do Recife - RMR, principalmente nas periferias da cidade e locais de encostas. Os riscos nessas áreas são agravados pelas ações antrópicas, aliados as precipitações pluviométricas que podem comprometer ainda mais esses locais.

As regiões de elevado relevo, quando ocupadas sem o devido amparo técnico de engenharia, costumam apresentar deslizamentos (Assis et al., 2017). As áreas sem vegetação causam exposição do solo e perda da estruturação superficial concedidas pelas raízes, bem como o aumento da infiltração e exposição a processos erosivos que podem evoluir causando deslizamento das encostas (Cerqueira et al., 2021). Sendo assim, o gerenciamento urbanístico e ambiental adequado se faz necessário para que nessas áreas não ocorram desastres (Nascimento et al., 2020).

\section{Resíduos Sólidos Urbanos}

A geração de Resíduos Sólidos Urbanos - RSU sofreu um aumento substancial na última década, no entanto, a quantidade de resíduos coletados em todas as regiões do Brasil também aumentou. Os Resíduos de Construção e Demolição RCD coletados pelos municípios em 2010, no Brasil, registraram 33 milhões de toneladas, em 2019 esse quantitativo aumentou para 44,5 milhões. Até 2050, o país terá um acréscimo de quase 50\% dos RSU, comparado ao ano base de 2019 (ABRELPE, 2020).

Os resíduos gerados pelas atividades econômicas da construção, manutenção e demolição das obras civis, definem o termo RCD. Sua composição varia conforme o tipo de ação, que pode ser construção, demolição ou reforma; e quanto ao tipo de estrutura e de técnica construtiva (Gálvez-Martos et al., 2018).

A construção civil é um dos setores que mais causam impactos ao meio ambiente, e um dos motivos é a alta quantidade de resíduos gerados pelo setor. Segundo Nascimento et al. (2020) um dos principais problemas de degradação ambiental, é a geração de resíduos que cresce à medida em que a população aumenta, além da exploração irregular de áreas de encosta devido ao crescimento demográfico, comum nos países em desenvolvimento (Zambon \& Salvatti, 2018). 
A reciclagem e o reaproveitamento de materiais descartados se relacionam a fatores como cultura, programas de coleta seletiva, isenção fiscal, entre outros. E o sucesso da reciclabilidade de materiais descartados depende diretamente da viabilidade econômica (Silva, 2018).

Na Europa não é diferente do Brasil, os RCD’s constituem uma fração aproximada de 30\% de todos os resíduos gerados. Novos objetivos e metas foram propostos pela Comissão Europeia para minimizar os impactos, como o uso da economia circular. A implementação sistemática dessas práticas recomendadas pela comissão pode melhorar a eficiência dos recursos e reduzir os danos ao meio ambiente (Gálvez-Martos et al., 2018).

Enfim, a construção civil é uma das atividades que mais interferem no meio ambiente, seja pelas construções ou seja pelo consumo dos recursos naturais, além de ser uma das maiores geradoras de resíduos sólidos do planeta. Apesar de ser um dos setores mais importante da economia mundial, empregando uma parcela considerável da população, a atividade é responsável por grandes impactos ecológicos e por um índice substancial de acidentes de trabalho.

No entanto, a mudança do comportamento de uma população não se constrói apenas com a homologação de uma lei, é preciso muito mais para modificar o comportamento e as práticas enraizadas de uma população. Vale salientar que a separação e o descarte adequado dos resíduos na fonte geradora podem garantir a qualidade desses materiais recicláveis (Reis et al., 2017).

Um dos aspectos-chave para os planos estratégicos é o envolvimento das partes interessadas. Planejamento participativo e inclusivo, onde os "stakeholders" se reúnem regulamente para medir o desempenho do sistema, definir ou atualizar os objetivos, como também uma plataforma local, onde as atribuições de tomada decisão são facilitadas, são algumas das estratégias de gestão de resíduos. Os instrumentos econômicos têm a função de motivar produtores de resíduos a não enviar os RCD's para os aterros, reciclando mais e otimizando o reuso desses materiais. O rastreamento foi utilizado em um município da Espanha, onde a forma de execução é por meio de um depósito que é reembolsado ao contratante, quando o certificado de gestão de resíduos é apresentado às autoridades (Gálvez-Martos et al., 2018).

Existe também o Plano de Gestão de Resíduos Local - PGRL que na fase de projeto busca identificar os materiais a serem recuperados, reutilizados, reciclados eliminados durante a construção ou demolição. Ainda nessa fase são definidos os instrumentos de monitoramento, coleta e as práticas que serão adotadas durante o processo. Na fase de implementação do PGRL a comunicação é fundamental entre as partes interessadas, treinamentos devem ser executados regularmente, além dos locais de armazenagem identificados e de fácil acesso para o sucesso do trabalho (Gálvez-Martos et al., 2018).

\section{Drenagem Urbana e Saneamento}

Com o aumento da população global e necessidade de água potável, a importância dos recursos hídricos subterrâneos aumentou consideravelmente. A maior parte da água doce mundial é armazenada nas regiões polares e uma pequena parcela dessa armazenagem em aquíferos subterrâneos. A água doce do planeta terra corresponde a 3\% da totalidade hídrica (Kalhor et al., 2019; Kalhor, 2019).

Nas áreas urbanizadas o escoamento provocado pela precipitação é impedido de se infiltrar no solo para recarregar as águas subterrâneas. A impermeabilização do solo decorrente dessa urbanização não só impacta o abastecimento das águas subterrâneas como influi no escoamento superficial das chuvas e na evapotranspiração das águas. O excesso de água se transforma em esgoto que podem causar alagamento, contaminação do lençol freático e assoreamento dos sistemas de drenagem. (Kalhor \& Emaminejad, 2019). 


\section{Análise de Risco}

O conceito de risco é utilizado em diversas áreas do conhecimento, como os riscos econômicos, tecnológicos, sociais, industriais, naturais e ambientais. Conforme o relatório da International Strategy for DisasterReduction (ISDR, 2007) o risco pode ser definido como uma possibilidade de consequências, as quais podem ocorrer perdas (mortes, ferimentos, propriedades, meios de subsistência, interrupção de atividade econômica, destruição ambiental). O processo de análise de risco inclui a identificação da natureza e a probabilidade de ocorrência, as quais são levados em consideração o contexto histórico, o modo de uso e a ocupação do solo.

\section{Caracterização da Área de Estudo}

O município de Jaboatão dos Guararapes está localizado na região litorânea do estado de Pernambuco e faz parte da Região Metropolitana do Recife (RMR), além de ser um dos mais antigos municípios do estado. Jaboatão dos Guararapes é formado por 35 bairros e suas principais vias de acesso são as rodovias BR-101, BR-232, BR-408, PE-007 e PE-008. Limita-se ao norte com o Recife, a oeste com Moreno, a noroeste com São Lourenço da Mata, ao sul com Cabo de Santo Agostinho e a leste com o Oceano Atlântico, ocupando uma área aproximada de 258,724 km², conforme ilustra a Figura 1 (IBGE, 2020).

A área de estudo é o Alto da Macaíba no bairro de Cavaleiro, que está localizado na Regional 2 (Regional Cavaleiro), a aproximadamente $14 \mathrm{~km}$ da cidade do Recife, capital de Pernambuco (IBGE, 2020).

Figura 1 - Localização do município de Jaboatão dos Guararapes/PE.

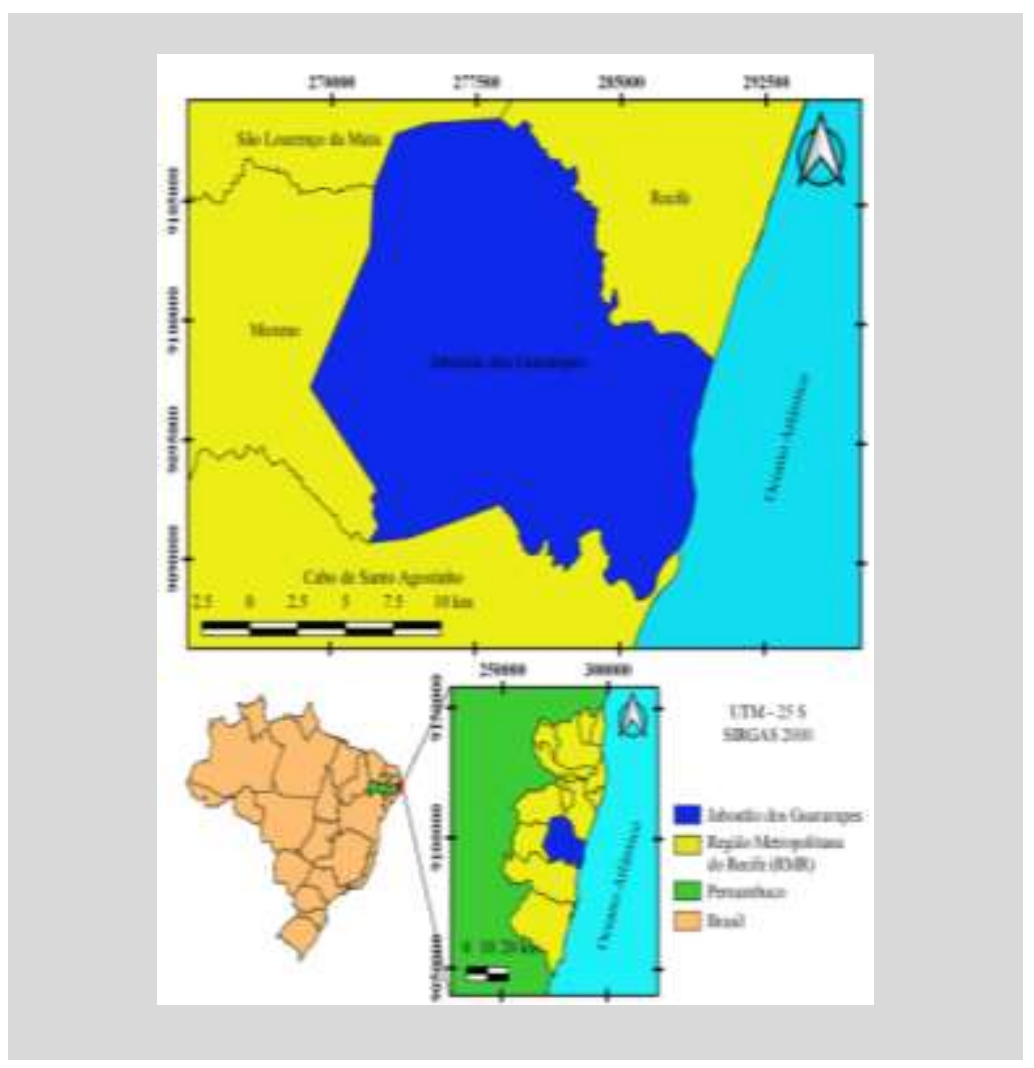

Fonte: Pessoa Neto et al. (2020)

Em 2010, o esgotamento sanitário adequado só atendia 45,40\% da população, a taxa de arborização das vias públicas era de 20,30\% e a taxa de urbanização de 19,10\%, segundo o Censo IBGE (2010). A região é densamente ocupada por edificações residenciais e está localizada em frente à estação de metrô Cavaleiro, de acordo com a Figura 2. 
Figura 2 - Localização da área estudada.

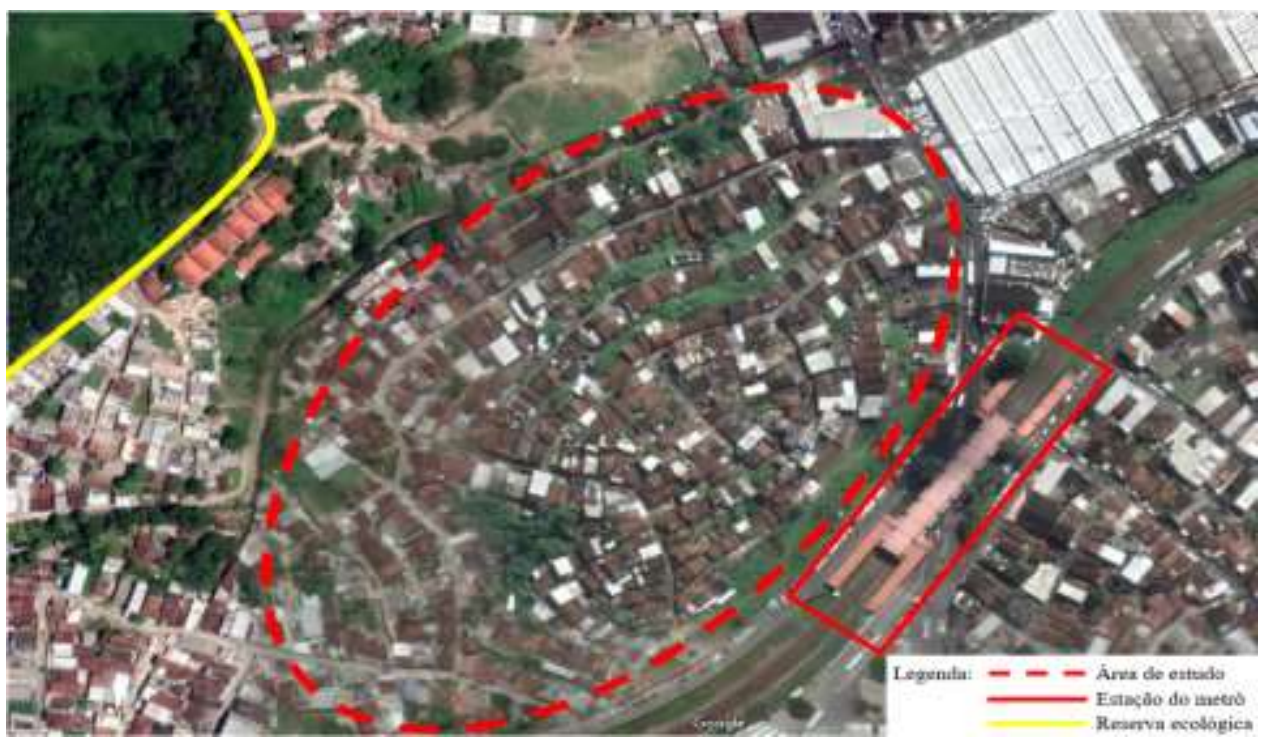

Fonte: Autores a partir de imagem do Google (2021)

A estação Cavaleiro faz parte da linha central do metrô do Recife e fica localizada entre as paradas Coqueiral e Floriano. É a partir da estação Cavaleiro que se inicia o ramal no sentido Jaboatão, denominado pelo METROREC como Centro-2 (Recife-Jaboatão dos Guararapes). Sua estrutura é composta por uma plataforma para os usuários que se dirigem a Jaboatão, e outra para os passageiros que têm o Recife como destino (METRORECIFE, 2021).

No talude existe obras de contenção em sua base (muros de arrimo), conforme a Figura 3, além de um sistema de drenagem com dispersores de energia, com o objetivo de escoar a água e evitar o surgimento de processos erosivos.

Figura 3 - Vista da encosta principal do alto da Macaíba.

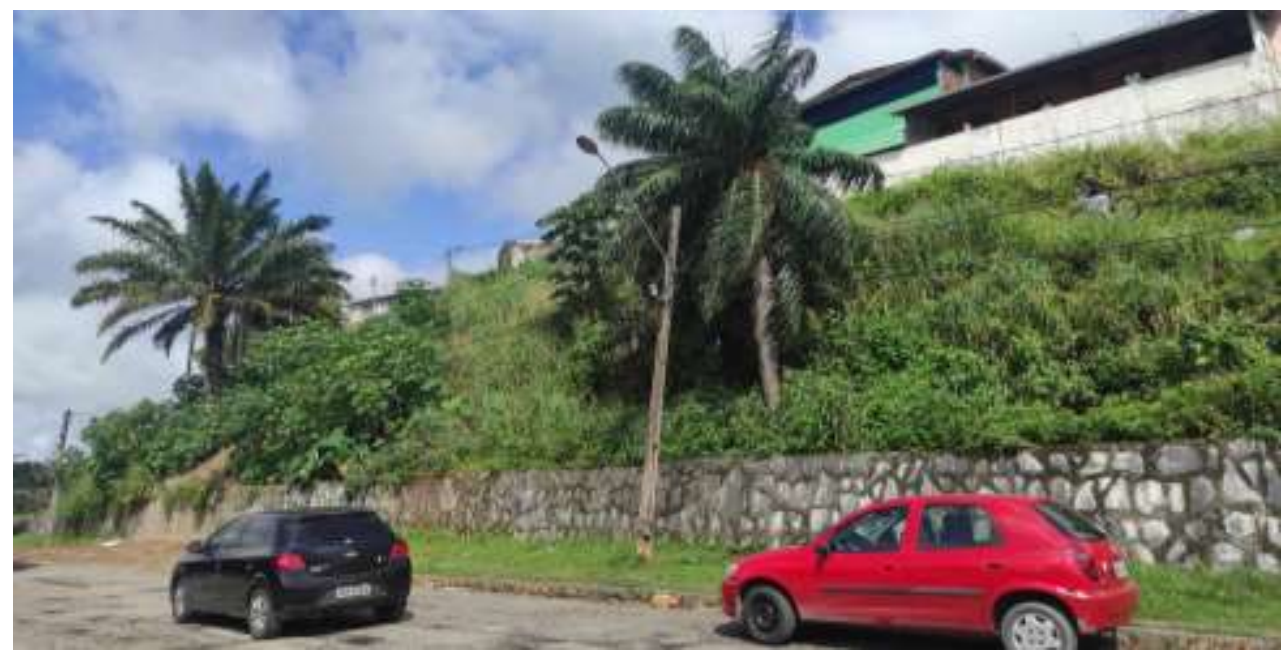

Fonte: Autores (2021).

\section{Aspectos Socioeconômicos}

O bairro de Cavaleiro é um dos mais populosos no município de Jaboatão dos Guararapes, concentra 38.677 dos 644.620 habitantes do município de acordo com o Censo IBGE 2010. Atualmente a população de Jaboatão dos Guararapes se encontra com 771.330 moradores, com uma renda mensal média de dois salários-mínimos, cerca de \$ 390 dólares. Em 2019, a taxa de ocupação da população era $14,69 \%$ e a renda per capita de $41,40 \%$ da população vivia com menos de $\$ 100$ dólares 
(IBGE, 2021). O Alto da Macaíba apresenta alta taxa de ocupação, apesar da localidade estar localizada em uma ZAB (Zona de Adensamento Construtivo Baixo).

\section{Vegetação e Relevo}

O bairro de Cavaleiro, em Jaboatão dos Guararapes se limita com a reserva florestal urbana de Jangadinha, que pertence ao bioma de mata atlântica (Agência Estadual de Meio Ambiente - CPRH - Companhia Pernambucana de Recursos Hídricos, 2021). Apesar de ser de alta densidade demográfica, apresenta gramíneas e ervas daninhas, além de árvores de médio porte.

O município de Jaboatão dos Guararapes possui três tipos de relevo em seu território: as planícies costeiras, os terraços marinhos e os morros/colinas. As áreas com altitudes elevadas chegam a atingir mais de 100 metros. A localidade estudada é caracterizada por morros de médio porte, com altitudes de 37 a 43 metros de altitude em relação ao nível do mar. Os principais tipos de solos encontrados no município são: latossolo vermelho amarelo distrófico, podzólico vermelho amarelo, podzol hidromórfico, solos aluviais, areias quartzosas marinhas e solos indiscriminados de mangues (Serviço Geológico do Brasil - CPRM, 2021).

\section{Clima}

O clima predominante na região é o tropical-úmido responsável por chuvas intensas em curto período, temperatura elevadas e alto teor de umidade, decorrente da massa tropical atlântica. O índice médio pluviométrico anual do município é de 988mm e tem uma temperatura média de $25.4^{\circ} \mathrm{C}$ (CLIMATE-DATA.ORG, 2021).

A área escolhida para o estudo foi definida com base no alto grau de desordenamento na ocupação, pela vegetação inapropriada e deposição irregular de RSU, favorecendo um contexto perigoso que converge para a possibilidade de deslizamentos no local por exemplo.

\section{Metodologia}

A pesquisa foi desenvolvida a partir da análise do processo de urbanização e da análise quantitativa e qualitativa dos impactos e riscos socioambientais da área. Para realização do estudo, todo o procedimento metodológico foi dividido em três etapas distintas:

- Coleta de dados;

- Mapeamento histórico da área;

- Análise qualitativa e quantitativa.

Os dados foram obtidos a partir de visita a área, para compor os parâmetros de risco ambiental que podem ocorrer sobre a encosta, são eles:

- Vegetação;

- Tipologia das edificações;

- Equipamentos de drenagem e saneamento;

- Descarte incorreto de resíduos sólidos. 
As imagens utilizadas no estudo foram obtidas junto a FIDEM (Agência Estadual de Planejamento e Pesquisas de Pernambuco CONDEPE/FIDEM) e com o apoio de um profissional especializado que posteriormente também executou a vetorização. Para a pesquisa foram contempladas as ortofotocartas dos anos de 1974, 1986, 2006 e 2021 . O software Google Earth Pro Versão 7.3.1.457 foi utilizado para a obtenção das imagens de 2006 e 2021.

De posse das imagens e das ortofotocartas georreferenciadas, foi possível compor os mapas vetorizados que ajudaram no processo de quantificação dos parâmetros da ocupação desordenada. Os indicadores utilizados para a análise foram separados em quatro tipologias, conforme Tabela 1.

Tabela 1 - Tipologias estudadas na análise temporal.

\begin{tabular}{l|l}
\multicolumn{1}{c|}{ Tipo } & \multicolumn{1}{c}{ Descrição } \\
\hline Mancha urbana & Ação antrópica: construções e/ou pavimentação do solo. \\
\hline Solo exposto & Solos sujeitos a processos erosivos. \\
\hline Vegetação & Árvores e/ou plantas rasteiras. \\
\hline
\end{tabular}

Fonte: Autores (2021).

A vetorização das ortofotocartas e das imagens foram feitas com a utilizando do software QGIS 3.12, com escalas de 1:25000. Cada tipologia teve um valor percentual atribuído e a análise temporal foi executada de forma automatizada pelo SIG - Sistema de Informações Geográficas.

O estudo foi dividido em duas partes distintas, separadas por um acontecimento ocorrido na localidade que serviu de marco para avaliar os movimentos de supressão de vegetação, solos expostos e mancha urbana. A área de estudo foi contemplada com a passagem da linha de metrô da Companhia Brasileira de Trens Urbanos (CBTU) tendo o seu início de operação em 24 de setembro de 1986.

Sendo assim, a análise temporal foi dividida entre o antes da implantação do metrô (1974 a 1986) e o depois (1986 a 2021) dessa implantação, buscando identificar os impactos provocados por essa intervenção local. Com essa divisão de tempo, os dois períodos passaram pelas mesmas análises a fim de verificar o processo de ocupação da localidade e consequente supressão de área verde.

Feita as análises, um quadro comparativo foi desenvolvido com o objetivo de evidenciar os impactos promovidos pela implantação/operação da linha metrô Centro-2. A análise temporal foi dividida em três ciclos distintos:

1975 - 1986: Período anterior à implantação/operação da linha de metrô Centro-2;

1986 - 2006: Período decorrente do ano de implantação/operação da linha até o ano de 2006;

2006 - 2021: Período de 2006 até a atualidade.

A partir dos resultados obtidos foi determinada a taxa média de ocupação anual, buscando verificar a celeridade no processo de ocupação, além de evidenciar o impacto promovido pela chegada do metrô na região e sua influência no processo de ocupação do local. Após análise de dados foi composta uma tabela com o resultado do processo de evolução analisado.

Para a verificação do grau de risco ambiental da área de estudo foi adotado a metodologia desenvolvida pelo Ministério das Cidades em parceria com o Instituto de Pesquisas Tecnológicas. É um modelo baseado na geotecnia para a avaliação do risco de deslizamentos. É composto por sete passos e tem como resultado uma classificação de risco. 
$1^{0}$ Passo - Dados gerais sobre a moradia: coleta dos dados gerais sobre a moradia ou grupo de moradias. Devem ser levantados dados a respeito da localização, tipo de moradia, condições de acesso.

$2^{\circ}$ Passo - Caracterização do local: caracterizar o tipo de talude, tipo de material, presença de materiais, inclinação da encosta e distância da moradia do topo ou base do talude.

$3^{\circ}$ Passo - Água: verificar a ocorrência de água no local, sua origem e seu destino e o que ocorre com a água da chuva.

$4^{\circ}$ Passo - Vegetação no talude ou proximidades: verificar se o tipo de vegetação no local traz benefícios ou prejuízos à segurança da encosta e anotar a vegetação encontrada.

$5^{\circ}$ Passo - Sinais de movimentação: visualizar que o local apresenta trincas, degraus de abatimento, inclinação de árvores, postes ou muros, "embarrigamento" de paredes.

$6^{0}$ Passo - Tipos de processos de instabilização esperados ou ocorridos: levando em consideração os itens anteriores, apontar qual o tipo de movimentação de massa esperado.

$7^{\circ}$ Passo - Determinação do grau de risco: o grau de risco será determinado a partir de padrões preestabelecidos e irão resultar em uma das classificações propostas. (Brasil, 2007)

O Quadro 1 apresenta os critérios que determinam o grau de risco ambiental, variando em R1 (grau baixo), R2 (grau médio), R3 (grau alto) e R4 (grau muito alto), conforme a descrição dos condicionantes geológico-geotécnicos.

Quadro 1 - Critérios para a determinação dos graus de risco.

\begin{tabular}{|c|c|}
\hline $\begin{array}{c}\text { Grau de } \\
\text { probabilidade }\end{array}$ & Descrição \\
\hline $\begin{array}{c}\text { R1 } \\
\text { Baixo }\end{array}$ & $\begin{array}{l}\text { 1. os condicionantes geológico-geotécnicos predisponentes (inclinação, tipo de terreno etc.) e o nível de intervenção } \\
\text { no setor são de baixa ou nenhuma potencialidade para o desenvolvimento de processos de deslizamentos e } \\
\text { solapamentos. } \\
\text { 2. não se observa(m) sinal/feição/evidência(s) de instabilidade. Não há indícios de desenvolvimento de processos de } \\
\text { instabilização de encostas e de margens de drenagens. } \\
\text { 3. mantidas as condições existentes não se espera a ocorrência de eventos destrutivos no período compreendido por } \\
\text { uma estação chuvosa normal. }\end{array}$ \\
\hline $\begin{array}{c}\text { R2 } \\
\text { Médio }\end{array}$ & $\begin{array}{l}\text { 1. os condicionantes geológico-geotécnicos predisponentes (inclinação, tipo de terreno etc.) e o nível de intervenção } \\
\text { no setor são de média potencialidade para o desenvolvimento de processos de deslizamentos e solapamentos. } \\
\text { 2. observa-se a presença de algum(s) sinal/feição/ evidência(s) de instabilidade (encostas e margens de drenagens), } \\
\text { porém incipiente(s). Processo de instabilização em estágio inicial de desenvolvimento. } \\
\text { 3. mantidas as condições existentes, é reduzida a possibilidade de ocorrência de eventos destrutivos durante episódios } \\
\text { de chuvas intensas e prolongadas, no período compreendido por uma estação chuvosa. }\end{array}$ \\
\hline $\begin{array}{c}\text { R3 } \\
\text { Alto }\end{array}$ & $\begin{array}{l}\text { 1. os condicionantes geológico-geotécnicos predisponentes (inclinação, tipo de terreno etc.) e o nível de intervenção } \\
\text { no setor são de alta potencialidade para o desenvolvimento de processos de deslizamentos e solapamentos. } \\
\text { 2. observa-se a presença de significativo(s) sinal/ feição/ evidência(s) de instabilidade (trincas no solo, degraus de } \\
\text { abatimento em taludes etc.). Processo de instabilização em pleno desenvolvimento, ainda sendo possível monitorar a } \\
\text { evolução do processo. } \\
\text { 3. mantidas as condições existentes, é perfeitamente possível a ocorrência de eventos destrutivos durante episódios de } \\
\text { chuvas intensas e prolongadas, no período compreendido por uma estação chuvosa. }\end{array}$ \\
\hline $\begin{array}{c}\text { R4 } \\
\text { Muito Alto }\end{array}$ & $\begin{array}{l}\text { 1. os condicionantes geológico-geotécnicos predisponentes (inclinação, tipo de terreno etc.) e o nível de intervenção } \\
\text { no setor são de muito alta potencialidade para o desenvolvimento de processos de deslizamentos e solapamentos. } \\
\text { 2. os sinais/feições/evidências de instabilidade (trincas no solo, degraus de abatimento em taludes, trincas em } \\
\text { moradias ou em muros de contenção, árvores ou postes inclinados, cicatrizes de deslizamento, feições erosivas, } \\
\text { proximidade da moradia em relação à margem de córregos etc.) são expressivas e estão presentes em grande número } \\
\text { ou magnitude. Processo de instabilização em avançado estágio de desenvolvimento. É a condição mais crítica, sendo } \\
\text { impossível monitorar a evolução do processo, dado seu elevado estágio de desenvolvimento. } \\
\text { 3. mantidas as condições existentes, é muito provável a ocorrência de eventos destrutivos durante episódios de chuvas } \\
\text { intensas e prolongadas, no período compreendido por uma estação chuvosa. }\end{array}$ \\
\hline
\end{tabular}

Fonte: Brasil (2007, p. 64)

Além da verificação do processo, foi feito a análise do impacto provocado pela instalação da linha do metrô na região. Foram levantados os pontos positivos e negativos após sua implantação. Realizou-se um levantamento quantitativo de equipamentos instalados (educação, saúde, lazer etc.) além da verificação da rede rodoviária do local, evidenciando através de 
visita "in loco" o estado das vias públicas. Verificou-se a existência de sistemas de drenagem pluvial, saneamento básico e/ou de abastecimento da comunidade. E sob a encosta foi realizado um levantamento quantitativo dos pontos de RSU's, mapeando e caracterizando os resíduos a fim de identificar o grau de comprometimento da encosta do Alto da Macaíba.

\section{Resultados}

\section{Impactos da Implantação da Linha Centro-2 do Metrô}

Por meio dos mapas vetorizados foi possível constatar a evolução da ocupação desordenada. A implantação da estação Cavaleiro do metrô foi extremamente relevante na ocupação da localidade. Os impactos ambientais podem ser observados na Tabela 2, a partir dos parâmetros de ocupação, onde as taxas de variações negativas (-) representam redução, enquanto as positivas (+) aumento da região analisada. A área está em hectare e a taxa de variação está em porcentagem.

Tabela 2 - Área e taxa de variação.

\begin{tabular}{l|c|c|c|c|c|c|c|c}
\hline \multirow{2}{*}{ Tipo } & \multicolumn{3}{|c|}{ Área (ha) } & \multicolumn{4}{c}{ Taxa (\%) } \\
\cline { 2 - 9 } & Antes do metrô & Depois do metrô & Antes do metrô & \multicolumn{2}{c}{ Depois do metrô } & Nos 46 anos \\
\cline { 2 - 9 } & $\mathbf{1 9 7 5}$ & $\mathbf{1 9 8 6}$ & $\mathbf{2 0 0 6}$ & $\mathbf{2 0 2 1}$ & $\mathbf{1 9 7 5}$ a 1986 & $\mathbf{1 9 8 6}$ a 2006 & $\mathbf{2 0 0 6}$ a 2021 & $\mathbf{1 9 7 5}$ a 2021 \\
\hline Mancha urbana & 1,09 & 2,04 & 4,57 & 4,09 & $13,77 \%$ & $36,67 \%$ & $-6,95 \%$ & $55,22 \%$ \\
\hline Solo exposto & 1,63 & 2,04 & 0,43 & 0,42 & $5,94 \%$ & $-23,33 \%$ & $-0,14 \%$ & $-17,54 \%$ \\
\hline Vegetação & 4,09 & 2,72 & 1,81 & 1,51 & $-19,86 \%$ & $-13,19 \%$ & $-4,35 \%$ & $-37,39 \%$ \\
\hline
\end{tabular}

Fonte: Autores a partir das imagens vetorizadas (2021)

No ano de 1975 se verifica a presença de vegetação nativa em grande volume, enquanto a mancha urbana da localidade se apresentava em pequeno quantitativo, que representavam respectivamente cerca de 59,27\% (4,09ha) e $15,80 \%$ (1,09ha) dos 6,90ha que compõe a área de estudo. A Figura 4 apresenta os resultados obtidos após análise no QGIS 3.21, do ano de 1975.

Figura 4 - Avaliação da área no ano de 1975.

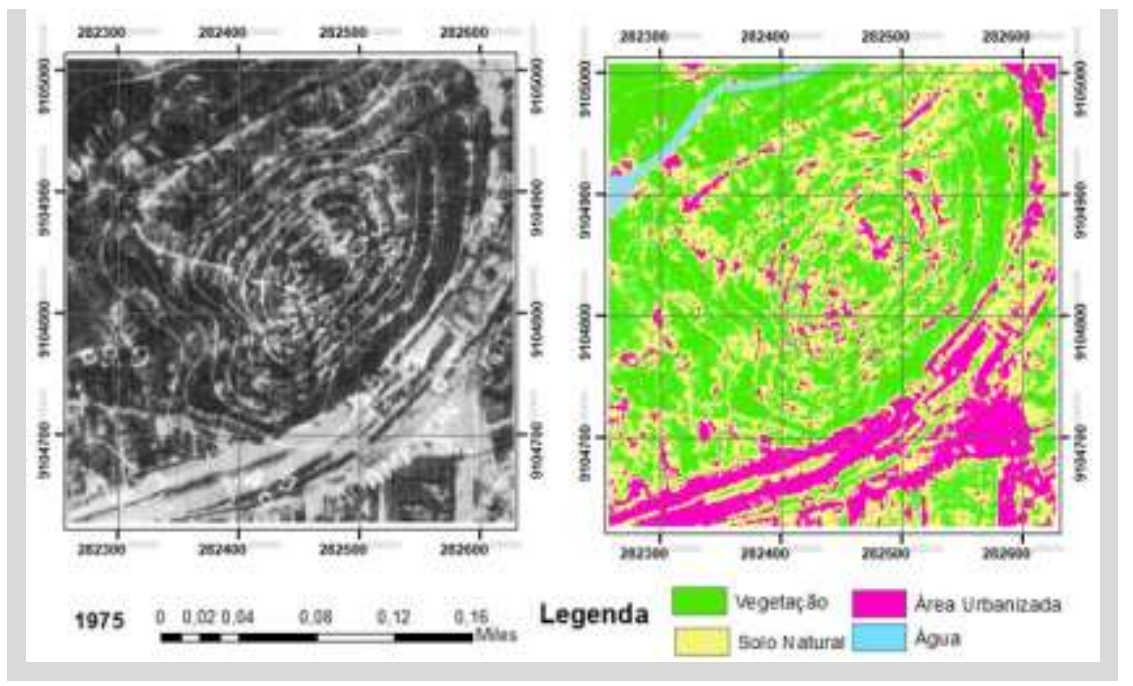

Fonte: Autores (2021)

Ainda se evidencia uma área de solo exposto de 1,63ha, equivalente a 23,62\% da área de estudo. Apesar da distância da localidade estudada, com base nos resultados obtidos, é possível apontar uma taxa de ocupação (mancha urbana) moderada. Sendo essa ocupação motivada não pelas comodidades proporcionadas, mas pela condição socioeconômica da população. 
Avaliando o ano de 1986, ano de início da operação da linha Centro-2, percebe-se o avanço da mancha urbana, apresentando um incremento de $87,15 \%$ em relação a 1975 , com um total de 2,04ha e um crescimento da mancha de 0,0863 ha/ano em média. Da mesma forma com a vegetação, verifica-se uma diminuição de 1,37ha da área inicial, com uma supressão de 33,50\% no período de 11 anos, equivalente a cerca de 0,125ha/ano. Também se observou o aumento de solo exposto, 25,15\% correspondendo a uma área de 0,41ha e um crescimento médio de 0,037ha/ano. Os resultados obtidos mostram já na primeira faixa temporal movimento dos parâmetros que indicam processos de ocupação da área de estudo. A Figura 5 apresenta os resultados obtidos após análise no QGIS 3.21, do ano de 1986.

Figura 5 - Avaliação da área no ano de 1986.

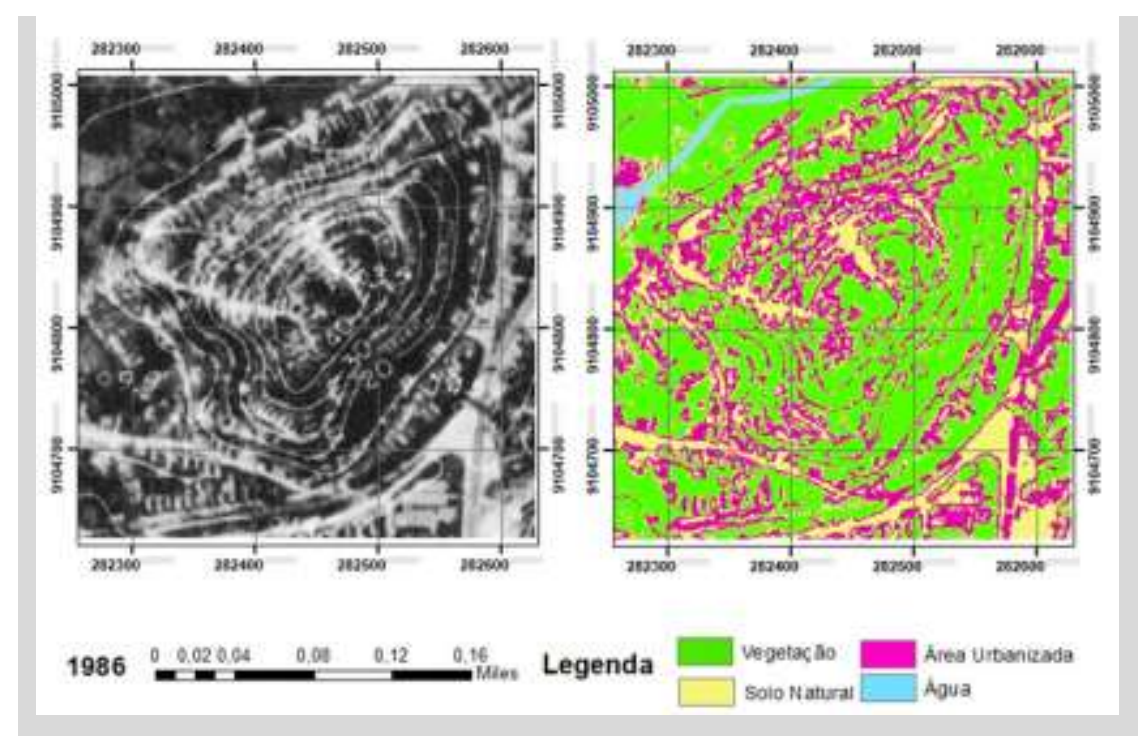

Fonte: Autores (2021)

No ano de 2006 o incremento de mancha urbana foi de 2,53ha, isso representa um aumento de 124,00\%, com um avanço médio de 0,127 ha/ano. No período entre 1986 a 2006, a diminuição da vegetação foi menor do que o intervalo anterior, mesmo assim a supressão foi em média 0,91ha, onde se verificou uma diminuição de 13,19\%, com uma média de 0,046 ha/ano. Um ponto relevante do período avaliado foi a diminuição de solo exposto da localidade, com uma supressão de 23,33\%, e uma diminuição média da área de 0,081 ha/ano. A Figura 6 apresenta os resultados obtidos após análise no QGIS 3.21 , do ano de 2006 . 
Figura 6 - Avaliação da área no ano de 2006.

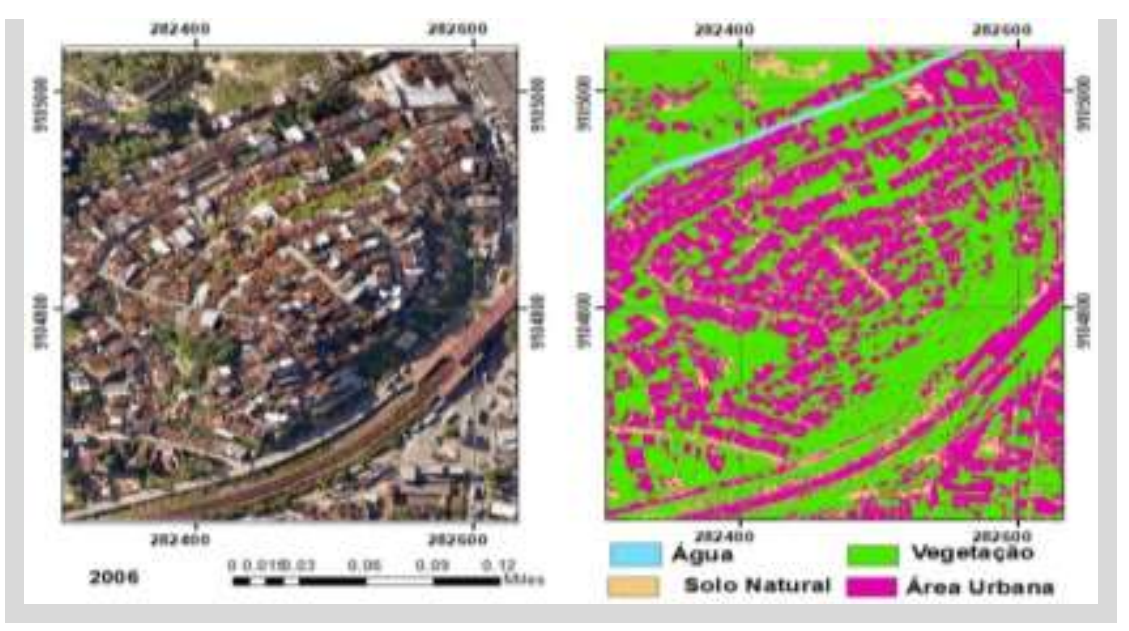

Fonte: Autores (2021)

Em 2021, o movimento evolutivo é similar ao observado no ano de 2006. No parâmetro de mancha urbana se verifica um leve declínio de 6,95\%, o que não modifica de forma substancial o cenário da localidade. O solo exposto apresentou uma redução de 0,01 ha quase inalterado na faixa temporal. A Figura 7 apresenta os resultados após análise no QGIS 3.21, do ano de 2021.

Figura 7 - Avaliação da área no ano de 2021.

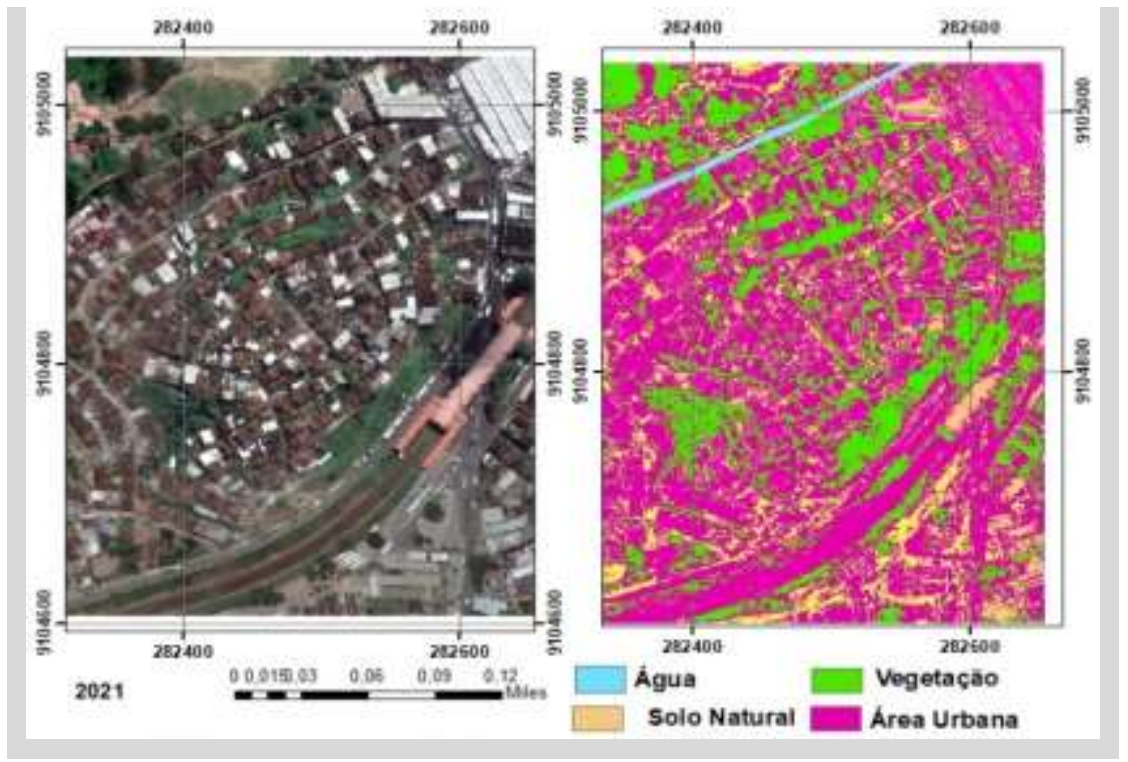

Fonte: Autores (2021)

Analisando os dados dos períodos distintos, antes e depois da implantação/operação da linha Centro-2 do metrô, ficou evidenciado que o evento influenciou consideravelmente o processo de ocupação da área. A Tabela 3 mostra que em 1986 a mancha urbana era de 2,04ha e que em 2021 passou para 4,09ha. A área de cobertura vegetal passou de 2,72ha para 1,51ha e a área de solo exposto passou de 2,04 para 0,42 hectares. 
Tabela 3 - Resultado do estudo.

\begin{tabular}{l|c|c}
\hline \multicolumn{1}{c}{ Descrição } & Área (ha) & Taxa \\
\hline Mancha urbana & 2,04 & $29,56 \%$ \\
\hline Antes do metrô & 4,09 & $71,01 \%$ \\
\hline Depois do metrô & 2,04 & $29,57 \%$ \\
\hline Solo exposto & 0,42 & $6,09 \%$ \\
\hline Antes do metrô & 2,72 & $39,42 \%$ \\
\hline Depois do metrô & 1,51 & $21,88 \%$ \\
\hline Vegetação & \multicolumn{2}{c}{} \\
\hline Antes do metrô & \multicolumn{2}{c}{} \\
\hline Depois do metrô &
\end{tabular}

Fonte: Autores (2021).

Sendo assim, os três parâmetros utilizados (mancha urbana, supressão vegetal e solo exposto) apontaram que houve um aumento de ocupação do solo e uma diminuição do solo exposto e da vegetação local.

\section{Determinação do Grau de Risco da Encosta}

\section{Análise das Ocupações}

Os problemas observados na comunidade do Alto da Macaíba, em Cavaleiro, retratam a realidade vivenciada pela maioria da população pobre que vive em áreas urbanas do país. O crescimento desordenado associado a ocupações de áreas inadequadas e a falta de saneamento básico, são alguns dos fatores que mais causam impactos ambientais. A falta de manutenção regular por parte do serviço público e os problemas de ordem educacional por parte da população contribuem na instalação do caos nas cidades.

Evidencia-se atendimento precário ou nulo da comunidade quanto ao ordenamento das vias públicas. Em sua grande maioria não apresenta urbanização adequada, ausência de sistemas de drenagem de águas pluviais, calçadas de meio fio ou pavimentação asfáltica. A maioria da população não possui acesso a esses equipamentos urbanos mínimos, agravando ainda mais os níveis de risco ambiental da área.

A deficiência da atuação do poder público na comunidade e o baixo poder econômico dos residentes, refletem a falta de padrão e controle construtivo das unidades residenciais do local, assim como a carência dos serviços de coleta de esgotos da localidade. A Figura 8 apresenta a área de estudo que evidencia a falta de planejamento urbanístico e amparo técnicoconstrutivo.

Figura 8 - Vistas de acessos ao Alto da Macaíba.

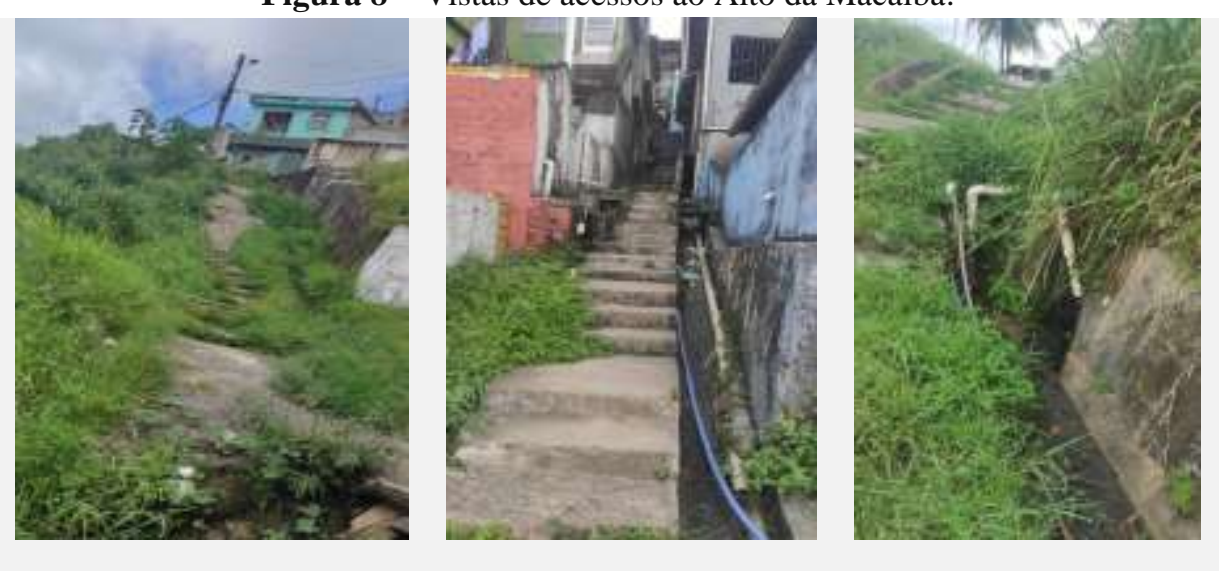

Fonte: Autores (2021) 
A área é quase toda pavimentada, com um cimentado feito pelos próprios moradores, o que aumenta o escoamento superficial das chuvas, sobrecarrega o sistema de drenagem e impede a recarga dos reservatórios subterrâneos. Os dispositivos de drenagem existente também apresentaram problemas, tais como: presença de vegetação obstruindo a passagem da água, despejo irregular de esgoto no sistema, presença de lixo e partes da estrutura danificada. A Figura 9 mostra alguns desses problemas.

Figura 9 - Presença de vegetação, resíduos sólidos e descarte irregular de águas cinzas.

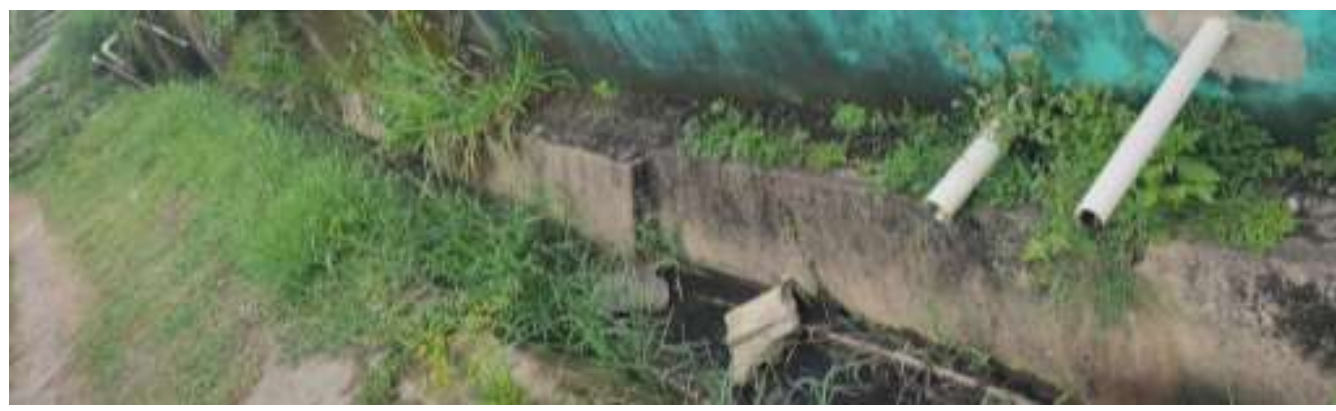

Fonte: Autores (2021).

$\mathrm{Na}$ parte da encosta a preocupação ficou por conta da vegetação inapropriada e do descarte de resíduos sólidos. Destaca-se a presença de coqueiros e palmeiras. Em algumas partes foi verificado a presença de tela argamassada e residências com três pavimentos, Figura 10.

Figura 10 - Imagens da encosta principal defronte a estação do metrô Cavaleiro.
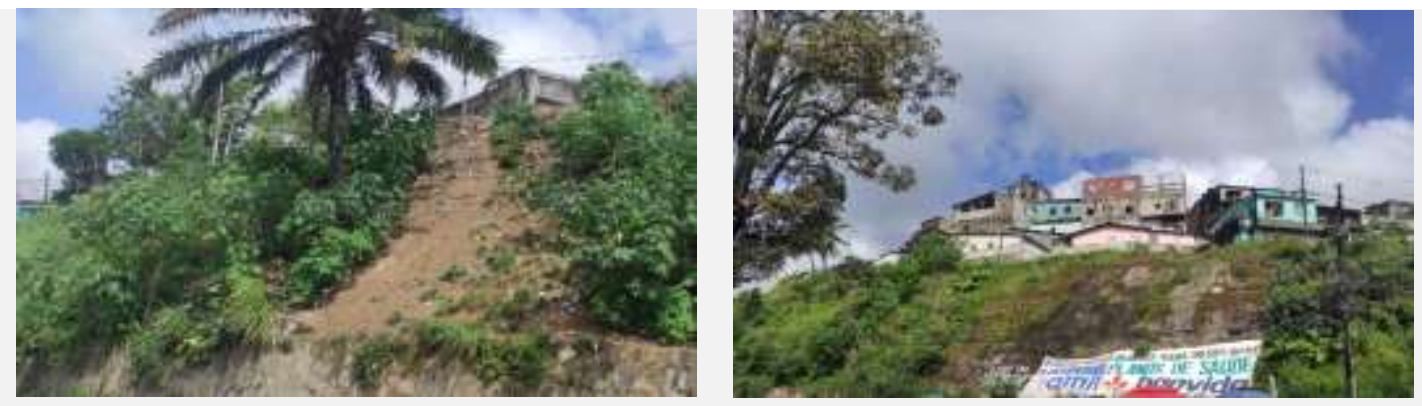

Fonte: Autores (2021).

A comunidade dispõe de um posto de saúde, três escolas e dois anexos. Além do processo de verticalização da área por falta de espaço, o sistema viário é muito complicado devido a supressão que sofreu pela ocupação antrópica.

Por meio dos mapas vetorizados foi possível constatar a evolução da ocupação desordenada. A implantação da estação Cavaleiro do metrô foi extremamente relevante na ocupação da localidade. Os impactos ambientais podem ser observados na Tabela 3, a partir dos parâmetros de ocupação, onde as taxas de variações negativas (-) representam redução, enquanto as positivas (+) aumento da área analisada. A área está em hectare e a taxa de variação está em porcentagem.

\section{Deposição Irregular de RSU}

O lixo foi um dos indicadores que mais chamou atenção na encosta principal, voltada para a estação do metrô, onde apesar de haver coleta de forma regular o comércio do entorno contribui para o descarte irregular dos resíduos. É preciso salientar que questões de ordem educacional também são responsáveis por grande parcela da disposição inapropriada do lixo. 
A Figura 11 apresenta o descarte irregular em dois pontos diferentes: no alto da encosta (a), resíduo comum; na base da encosta, a deposição de RCD (b).

Figura 11 - Descarte irregular de resíduos.
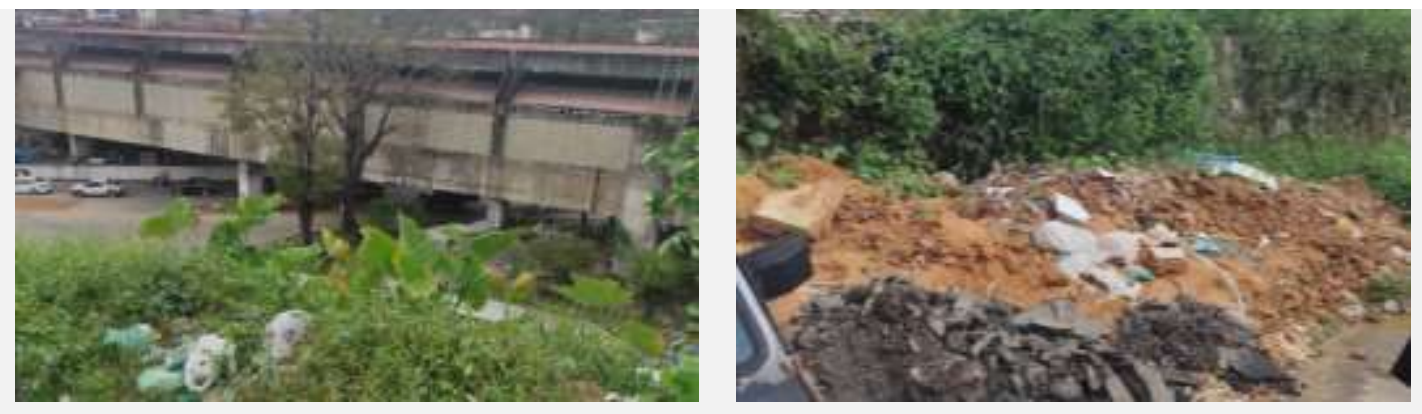

Fonte: Autores (2021).

Buscando quantificar e verificar os riscos ambientais que essa deposição pode promover foi feito o levantamento na encosta dos pontos de deposição de RSU's. A Figura 12 apresenta o mapa com o levantamento citado.

Figura 12 - Mapeamento das deposições de RSU.

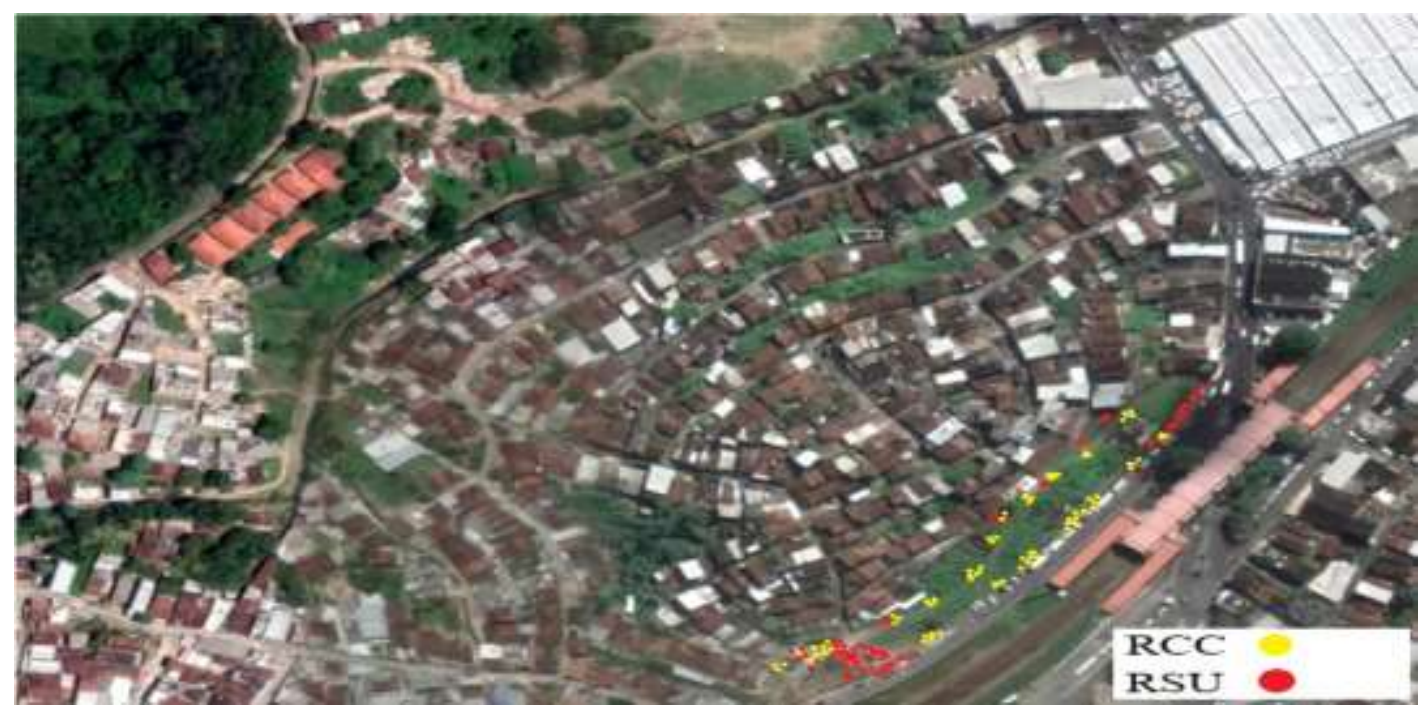

Fonte: Autores a partir de imagens do Google (2021)

A área tem um total 0,51ha, o que corresponde a 7,39\% do total analisado, e foi escolhida especificamente por ser um trecho descoberto, livre de edificações e ter apresentado pontos de deposição de RSU em praticamente todo seu desenvolvimento, além da deposição se evidencia capeamento cimentício em alguns trechos. A Tabela 4 apresenta o mapeamento realizado na encosta no morro da Macaíba. 
Tabela 4 - Mapeamento de pontos de deposição irregular.

\begin{tabular}{ccc}
\hline Tipo de resíduo & Quantidade & Representação (\%) \\
\hline RCC & 84 & $41,00 \%$ \\
RSU & 122 & $59,00 \%$ \\
& $\mathbf{2 0 6}$ & $\mathbf{1 0 0 , 0 0 \%}$ \\
\hline
\end{tabular}

Fonte: Autores a partir de visita ao local (2021)

Verifica-se a ocorrência de pontos de deposição em toda a encosta, sendo a maioria RSU de ordem orgânica, proveniente do descarte residencial e da atividade comercial. Nos demais pontos são os RCC's, provenientes em sua totalidade de construções de novas unidades habitacionais ou ampliação/reforma das existentes na área de estudo. O estreitamento das vias de acesso no interior da área ocorrido pelo processo de ocupação desordenada, associado com a dificuldade de acesso, contribui para essa deposição irregular, aumentando os ricos ambientais da encosta e da localidade como um todo.

Foram quantificados também pontos de descarte irregular de águas cinzas, provenientes das residências instaladas na área de estudo, totalizando 109 pontos de descarte diretamente sob a superfície da encosta. Outros 46 pontos foram igualmente quantificados sendo descartados nos equipamentos destinados a drenagem pluvial. Igualmente as deposições de resíduos, contribui de forma negativa, elevando o risco ambiental que acomete a localidade. Desta maneira foi possível compor a Tabela 5 a qual apresenta a determinação do grau de risco da encosta.

Tabela 5 - Determinação do grau de risco da encosta.

\begin{tabular}{|c|c|}
\hline PASSOS & Observações da visita técnica \\
\hline $1^{\circ} \mathrm{PASSO}$ & $\begin{array}{l}\text { Boa localização, perto de vias asfaltadas e de equipamento de mobilidade urbana de grande fluxo (linha metrô } \\
\text { centro-2: Recife-Jaboatão). As edificações da localidade em sua maioria são fruto de ocupações antrópicas, com } \\
\text { alto grau de desordenamento. As vias de acesso periféricas apresentam conformidade executiva com as normas } \\
\text { técnicas, diferentemente das vias internas da ocupação local, onde se verifica estreitamento das vias, } \\
\text { principalmente no centro da localidade, com impermeabilização do solo feito pelos ocupantes. }\end{array}$ \\
\hline $2^{\circ}$ PASSO & $\begin{array}{l}\text { A encosta é composta basicamente por material argilo-arenoso de boa compactação, e as residências da localidade } \\
\text { estão muito próximas a crista do talude. O mesmo também recebe deposição de RSU e RCC de toda a } \\
\text { comunidade, existindo pontos de deposição de RSU, proveniente da atividade comercial exercida na base da } \\
\text { mesma (centro comercial de Cavaleiro). }\end{array}$ \\
\hline $3^{\circ} \mathrm{PASSO}$ & $\begin{array}{l}\text { Verifica-se descarte de águas cinzas diretamente na encosta, uma vez que a localidade não é assistida por um } \\
\text { sistema de esgotamento sanitário, verifica também descarte de parte das águas proveniente de sistemas de } \\
\text { drenagem instalados na encosta, sendo isso em decorrência do comprometimento estado de conservação dos } \\
\text { equipamentos. }\end{array}$ \\
\hline $5^{\circ} \mathrm{PASSO}$ & $\begin{array}{l}\text { Não se evidenciou movimentação na encosta, uma vez que, a mesma tem em todo seu desenvolvimento } \\
\text { equipamento de contenção tais como muro de arrimos em sua base e em região intermediária. Também foram } \\
\text { evidenciados equipamentos de drenagem de águas pluviais, com canaletas de escoamento. }\end{array}$ \\
\hline $6^{\circ} \mathrm{PASSO}$ & $\begin{array}{l}\text { É possível a ocorrência de um incidente de grande porte na região, com ocorrência de deslizamento, } \\
\text { comprometimento de residências localizadas na crista do talude, além do sistema rodoviário localizado na base da } \\
\text { encosta. }\end{array}$ \\
\hline $7^{\circ} \mathrm{PASSO}$ & Identificação Grau de Risco R2 para a encosta avaliada. \\
\hline
\end{tabular}

Fonte: Autores a partir de visita ao local (2021)

\section{Conclusões}

A avaliação no Alto da Macaíba, buscou identificar os efeitos decorrentes do processo de ocupação irregular no intervalo de 46 anos (1975 a 2021). A análise teve como marco divisor a implantação/operação da linha Centro-2 da CBTU na 
região, onde se evidenciou que implantações de equipamentos de grande porte, como é o caso da estação Cavaleiro, obra de mobilidade urbana, que atende um número significativo de usuários todos os dias, influencia no processo de urbanização.

As taxas de mancha urbana, apresentou um crescimento de $93,02 \%$, enquanto solo exposto e supressão vegetal tiveram uma redução de $62,83 \%$ e 52,98\%, respectivamente. A deficiência do sistema de drenagem, a inexistência de esgotamento sanitário e de um planejamento urbanístico, apontam a falta de amparo à comunidade. Estes valores podem servir como dados importantes, para que o poder público possa adotar medidas de prevenção que elimine ou mitiguem as causas das ocorrências, contribuindo para a redução dos riscos. Para estudos futuros sugere-se a avaliação dos impactos gerados por essa ocupação desordenada nos corpos hídricos do local.

\section{Referências}

ABRELPE. Associação Brasileira de Empresas de Limpeza Pública e Resíduos Sólidos Especiais. Panorama dos resíduos sólidos no Brasil (2020).

Araújo, F. N. F., Araújo, V. B., Martins, M. F. \& Barbosa, M. F. N. Impactos socioambientais provocados por resíduos sólidos em terrenos baldios de Campina Grande - PB: um olhar fotográfico (2018). In: Santos, J. P. de O., Silva, R. C. P., Mello, D. P. de, El-Deir, S. G. (Orgs.). Resíduos Sólidos: impactos socioeconômicos e ambientais. EDUFRPE. 1,104-120.

Assis, H. Y. E. G., Cesar, P. H., Rodrigues, J. G. V., Santos, E. G., Targino, C. K. D., Freire, E. M. X. \& Moreira, S. A. Análise de políticas socioambientais implicadas no caso de deslizamento de terra no bairro Mãe Luiza em Natal/RN (2017). Gaia Scientia, 11(2).

Basso, L., Weixter, C. A., Silva, B. M. D., \& Almeida, F. C. D. (2018). Gerenciamento da Drenagem Urbana: Um desafio multidisciplinar e multissetorial. Revista Conexão Eletrônica, 15(1).

Brasil. Lei $\mathrm{n}^{\circ}$ 12.305, de 2 de agosto de 2010. Institui a Política Nacional de Resíduos Sólidos, altera a Lei nº 9.605 , de 12 de fevereiro de 1998 , e dá outras providências. Ministério do Meio Ambiente, Brasília, DF.

BrasiL. Ministério das Cidades/Instituto de Pesquisas Tecnológicas - IPT (2007). Mapeamento de Riscos em Encostas e Margem de Rios. Brasília.

Brasil. Resolução CONAMA n ${ }^{\circ}$ 307, de 05 de julho de 2002. Estabelece diretrizes, critérios e procedimentos para a gestão dos resíduos da construção civil. Diário Oficial da República Federativa do Brasil.

Cerqueira, M. A., Santos, P. O. C., de Farias, V. N. C., Júnior, V. F. C., \& Barbosa, R. V. R. (2021). Análise temporal por sensoriamento remoto da supressão de vegetação nativa em vales na cidade de Maceió, Brasil. The Journal of Engineering and Exact Sciences, 7(1), $12151-01$.

CPRH - Agência Pernambucana do Meio Ambiente (2021). FURB Mata de Jangadinha. Pernambuco: CPRH. http://www2.cprh.pe.gov.br/uc/furb-mata-dejangadinha/

CPRM - Serviço Geológico Brasileiro (2021). Carta de suscetibilidade a movimentos gravitacionais de massa e inundação. Pernambuco: CPRM. http://www.cprm.gov.br/publique/Gestao-Territorial/Prevencao-de-Desastres/Cartas-de-Suscetibilidade-a-Movimentos-Gravitacionais-de-Massa-eInundacoes-5379.html

CLIMATE-DATA.ORG. (2021). Dados climáticos para cidades mundiais. https://pt.climate-data.org/america-do-sul/brasil/pernambuco/jaboatao-dosguararapes-33800/

Cremiato, R., Mastellone, M. L., Tagliaferri, C., Zaccariello, L., \& Lettieri, P. (2018). Environmental impact of municipal solid waste management using Life Cycle Assessment: The effect of anaerobic digestion, materials recovery and secondary fuels production. Renewable Energy, 124, $180-188$.

de Lima Andrade, E., Calheiros, S. Q. C., \& da Conceição, D. N. (2018). Áreas críticas à ocupação urbana sujeitas a deslizamento de terra na bacia hidrográfica do riacho Reginaldo, Maceió-AL. Revista Contexto Geográfico, 3(5), 01-11.

Gálvez-Martos, J. L., Styles, D., Schoenberger, H., \& Zeschmar-Lahl, B. (2018). Construction and demolition waste best management practice in Europe. Resources, Conservation and Recycling, 136, 166-178.

Gori, A., Blessing, R., Juan, A., Brody, S., \& Bedient, P. (2019). Characterizing urbanization impacts on floodplain through integrated land use, hydrologic, and hydraulic modeling. Journal of Hydrology, 568, 82-95.

Gouveia, N., Buzzo, M. L., Grossi, M. G. D. L., Souza, G. F. D., \& Muto, E. Y. (2019). Exposição ocupacional ao mercúrio em cooperativas de triagem de materiais recicláveis da região metropolitana de São Paulo, SP, Brasil. Ciência \& Saúde Coletiva, 24, 1517-1526.

IBGE - Instituto Brasileiro de Geografia e Estatística. Censo 2010. IBGE, 2010 https://cidades.ibge.gov.br/brasil/pe/olinda/panorama.

Kalhor, K. (2017). Assessment and modeling of groundwater flow and nitrate contamination within coastal karst aquifer of puerto rico (Doctoral dissertation, Northeastern University).

Kalhor, K., \& Emaminejad, N. (2019). Sustainable development in cities: Studying the relationship between groundwater level and urbanization using remote sensing data. Groundwater for Sustainable Development, 9, 100243. 
Research, Society and Development, v. 10, n. 17, e28101724352, 2021

(CC BY 4.0) | ISSN 2525-3409 | DOI: http://dx.doi.org/10.33448/rsd-v10i17.24352

Kalhor, K., Ghasemizadeh, R., Rajic, L., \& Alshawabkeh, A. (2019). Assessment of groundwater quality and remediation in karst aquifers: A review. Groundwater for sustainable development, 8, 104-121.

METRÔ RECIFE. Mapa, estações, notícias, horários. http://www.metrorecife.com.br/estacoes-cavaleiro/

Nascimento, L. A., Silva, T. A., Santos, M. J. P. \& Lafayette, K. P. V. Análise dos riscos ambientais decorrentes de ocupações irregulares em uma encosta do município de Olinda - PE (2020). In: Santana, R. F., Aragão Júnior, W. R., El-Deir, S. G. (Org.). Resíduos Sólidos: Desenvolvimento e Sustentabilidade. Recife: EDUFRPE, 91-101.

Pessoa Neto, A. G., Barbosa, I. M. B. R., Silva, S. R. \& Silva Junior, M. A. B. Análise espaço-temporal do uso e ocupação do solo no entorno do canal Olho d'Água, em Jaboatão dos Guararapes/PE (2020). In: XIII Encontro Nacional de Águas Urbanas, 2020, Anais do XIII Encontro Nacional de Águas Urbanas. Porto Alegre: ABRHidro, 1-10.

Ramón González, J. A., \& Aguilar, A. G. (2021). Irregular Urban Expansion, Change in Land Use and Environmental Deterioration in the Northern Periphery of the Puebla-Tlaxcala Metropolitan Zone: The Case of La Malinche National Park. Cuadernos de Geografía: Revista Colombiana de Geografía, 30(2), 441458.

Reis, D., Friede, R., \& Lopes, F. H. P. (2018). Política nacional de resíduos sólidos (Lei no 12.305/2010) e educação ambiental. Revista Interdisciplinar do Direito-Faculdade de Direito de Valença, 14(1), 99-111.

Silva, A. S., Morais, L. S., Santos, F. C. \& Nunes, K. B. Análise das características do solo na área de aterro em não conformidade no município de Pinheiros - MA (2020). In: Santana, R. F., Aragão Júnior, W. R., El-Deir, S. G. (Org.). Resíduos sólidos: desenvolvimento e sustentabilidade. Recife: EDUFRPE, 415424.

Silva, T. A., Santos, M. J. P., Lafayette, K. P. V. \& Silva, S. R. Impactos ambientais provenientes da expansão urbana em uma encosta do bairro de Dois Unidos em Recife-PE: Um olhar fotográfico (2018). In: Amorim, M., Garrido, M., Gonçalves, E., Fontes, A., Moraes, L. R., Almeida, R. \& Ferreira, M. V. G. (Org.). Saneamento no semiárido: modelo de gestão e promoção de tecnologias apropriadas, 1, 511-516.

Silveira, D. C., Carmo, R. F., \& Luz, Z. M. P. D. (2019). O planejamento de quatro áreas do Programa Vila Viva na cidade de Belo Horizonte, Brasil: uma análise documental. Ciência \& Saúde Coletiva, 24, 1165-1174.

Zambon, I., \& Salvati, L. (2018). Demographic dynamics, economic expansion and settlement dispersion in Southern Europe: contrasting patterns of growth and change in three metropolitan regions. Management Research and Practice, 10(2), 41-62. 